\title{
Dimensional Isotropy of 6H and 3C SiC Under Neutron Irradiation
}

Lance L Snead, ${ }^{1,}$ Yutai Katoh ${ }^{2}$, Takaaki Koyanagi ${ }^{2}$, Kurt Terrani², and Eliot D Specht ${ }^{2}$

1 Massachusetts Institute of Technology, Cambridge MA, USA

2 Oak Ridge National Laboratory, Oak Ridge TN, USA

*corresponding author: Snead@MIT.edu

\section{ABSTRACT}

This investigation experimentally determines the as-irradiated crystal axes dimensional change of the common polytypes of $\mathrm{SiC}$ considered for nuclear application. Single crystal $\alpha$-SiC (6H), $\beta$-SiC (3C), CVD $\beta$-SiC, and single crystal Si have been neutron irradiated near $60^{\circ} \mathrm{C}$ from $2 \times 10^{23}$ to $2 \times 10^{26} \mathrm{n} / \mathrm{m}^{2}$ (E>0.1 MeV), or about 0.02 to $20 \mathrm{dpa}$, in order to study the effect of irradiation on bulk swelling and strain along independent crystalline axes. Single crystal, powder diffractometry and density measurement have been carried out. For all neutron doses where the samples remained crystalline all $\mathrm{SiC}$ materials demonstrated equivalent swelling behavior. Moreover the $6 \mathrm{H}-\mathrm{SiC}$ expanded isotropically. The magnitude of the swelling followed a $\sim 0.77$ power law against dose consistent with a microstructure driven by single interstitial (carbon) mobility. Extraordinarily large $\sim 7.8 \%$ volume expansion in SiC was observed prior to amorphization. Above $\sim 0.9 \times 10^{25} \mathrm{n} / \mathrm{m}^{2}$ $(\mathrm{E}>0.1 \mathrm{MeV}$ ) all $\mathrm{SiC}$ materials became amorphous with an identical swelling: a $11.7 \%$ volume expansion, lowering the density to $2.84 \mathrm{~g} / \mathrm{cm}^{3}$. The as-amorphized density was the same at the $2 \times 10^{25}$ and $2 \times 10^{26} \mathrm{n} / \mathrm{m}^{2}(\mathrm{E}>0.1 \mathrm{MeV})$ dose levels. 


\section{Introduction}

Irradiation-induced anisotropic swelling of the hexagonal close packed crystal of $\alpha$ SiC-based ceramics has been postulated historically[1-3] , and recently implicated in, the irradiation-induced degradation of $\mathrm{SiC}$ ceramics. The root of this speculation has been the observed difference in the irradiation-induced properties (including strength) of irradiation-stable pyrolytic $\mathrm{SiC}$ (a faulted form of cubic $\beta \mathrm{SiC}$ ) and certain SiC ceramics processed with hexagonal $\alpha$-SiC. Such anisotropy and resulting degradation in properties does occur in many ceramics possessing trigonal crystal structures such as alumina (sapphire) $[4,5]$ and hexagonal structures such as silicon nitride,[6] aluminum nitride,[7] and beryllium oxide.[8] It is therefore reasonable that $\alpha-\mathrm{SiC}$ and other ceramics with a hexagonal crystal structure may display irradiation-induced differential expansion on the $<a>$ and $<c>$ axes leading to microcracking and loss of ceramic physical integrity.

For the case of single crystal alumina a modest $\sim 0.1 \%$ dilation in the $<a>$ axis occurs upon irradiation at $\sim 400^{\circ} \mathrm{C}$, negatively trending as irradiation temperature is increased. A more exaggerated dilation in the $<\mathrm{c}>$ axis occurs as a function of dose occurs for the same $400^{\circ} \mathrm{C}$ irradiation, resulting in just under $0.2 \%$ dilation, substantially increasing with irradiation temperature. This anisotropic expansion in the $<a>$ and $<c>$ direction has been implicated in the decreased mechanical strength that occurs by $1 \times 10^{26} \mathrm{n} / \mathrm{m}^{2}(\mathrm{E}>0.1 \mathrm{MeV})$ for alumina.[1] Similar, modest reductions in strength for polycrystalline alumina have been reported elsewhere in the literature.[4,5] For lower temperature irradiation (near $80^{\circ} \mathrm{C}$ ),[9] swelling along the $<\mathrm{a}>$ and $\left\langle\mathrm{c}>\right.$ axes of alumina are essentially identical until about $2.5 \times 10^{25} \mathrm{n} / \mathrm{m}^{2}$ $(\mathrm{E}>0.1 \mathrm{MeV}$,) at which point the $<\mathrm{c}>$ axis exhibits slightly greater swelling. The anisotropic swelling of $\mathrm{BeO}$ at similar irradiation temperatures occurs in a more exaggerated fashion beginning at a lower irradiation dose. While the $<a>$ axis monotonically expands to approximately $0.1 \%$ by $1 \times 10^{25} \mathrm{n} / \mathrm{m}^{2}(\mathrm{E}>1 \mathrm{MeV})$ the $<\mathrm{c}>$ axis expands to approximately $3.5 \%$ over the same dose range. The result of this large anisotropic expansion for $\mathrm{BeO}$ is the near complete loss of mechanical strength by $1 \times 10^{24} \mathrm{n} / \mathrm{m}^{2}(\mathrm{E}>1 \mathrm{MeV}$.)[8]

The literature on the irradiation effects of $\mathrm{SiC}$ includes a wide array of $\mathrm{SiC}$ ceramics including those fabricated from hexagonal $(\alpha)$ or cubic $(\beta)$ phases. A detailed discussion of the effects of irradiation on SiC properties can be found elsewhere.[10] Generally, the irradiation-stability of the $\beta$-phase $\mathrm{SiC}$ is founded on a relatively solid body of work on chemically vapor deposited (CVD) SiC, a highly-faulted form of pure $\beta$-SiC which can be of high purity. The stability of CVD SiC is generally contrasted with the instability of $\alpha$ and $\beta$ SiC ceramics formed through conventional processing methods, which demonstrate rapid irradiation-induced degradation of engineering properties. For example, the initial 1972 work of Matthews and Hutchings[11] discusses the behavior of reaction-bonded $\alpha$ and $\beta$-SiC-derived ceramics irradiated to a few tenths of a dpa at 400 and $700^{\circ} \mathrm{C}$, observing significant 
strength loss. In that paper the ceramic degradation was attributed to differential swelling of the $\alpha$-SiCl and $\beta$-SiC as well as the Si phase present at the grain boundaries. In follow-on work Matthews[12] studied irradiated $\alpha$-SiC powder, $\beta$ $\mathrm{SiC}$ powder, $\mathrm{Si}$ powders and their respective sintered ceramics finding little difference between the lattice-dilation of the two SiC polytypes at irradiation temperature above $400^{\circ} \mathrm{C}$ and up to a few dpa. Neutron irradiation studies carried out by Matheney[2] , Iseki[13] , Price [14] , Dienst[15] and Correli[16] all report significant strength decrease in conventionally processed $\alpha$-SiC ceramics and with the general consensus of internal strain and lack of grain boundary cohesion as the driving force behind degradation. Li and coworkers [17] have carried out Si ion irradiation at $1000^{\circ} \mathrm{C}$ of cubic $3-\mathrm{C} \mathrm{SiC}$, reporting anisotropic crystal swelling, though attributed this anisotropy to a Si-substrate effect.

In one study on very low dose $\mathrm{H}$ implantation into $\beta$-SiC films an initial contraction along the <a> axis was observed by Jiang et al.[18] Constantini [19] and Kerbirioui[20] provide a comparison of the accumulation of lattice disorder and resulting mechanical properties in Cree single crystal $\alpha-6 \mathrm{H}-\mathrm{SiC}$ and $\beta-3 \mathrm{C}-\mathrm{SiC}$ epitaxial layers indicating similar layer expansion. Pramono et al[21] studied the effect of implanted helium on the swelling behavior of irradiated $\alpha-6 \mathrm{H}-\mathrm{SiC}$ ceramics, providing data on the dilation of the $\langle\mathrm{a}>$ and $\langle\mathrm{c}\rangle$ axes, showing them to be essentially equivalent for irradiation at $300^{\circ} \mathrm{C}$ to $0.28 \times 10^{25}$ ( $\mathrm{E}>0.1 \mathrm{MeV}$.)

By comparing the available ion irradiation data with neutron irradiation data such as that of Matthews[12] and Price[22] it could be reasonably argued that no differential swelling exists between the most common $\alpha-6 \mathrm{H}$ and $\beta-3 \mathrm{C}$ SiC polytypes. Moreover, it could be similarly put forward that no large difference exists in irradiation-dilation between the major axes of the $6 \mathrm{H}$ alpha polytype of SiC. This lack of an anisotropic swelling response to irradiation, in contrast to the hexagonal crystals above, could have a number of explanations including the lack of mobility for both $\mathrm{Si}$ and $\mathrm{C}$ vacancies as well as the $\mathrm{Si}$ interstitial at these irradiation temperature. Regardless, the absolute comparison of the relative swelling difference under neutron irradiation, if any, between cubic and hexagonal forms of $\mathrm{SiC}$ has not been directly demonstrated. As this question is of current practical interest to the community this work has been carried out to provide such a direct comparison.

\section{Experimental}

Materials selected for this comparative study were single crystal Hoya $\beta-3 \mathrm{C}$ SiC, single crystal Cree Systems $\alpha-6 \mathrm{H} \mathrm{SiC}$, polycrystalline Rohm-Haas CVD SiC (a highly faulted $\beta-\mathrm{SiC}$ ), and single crystal $\mathrm{Si}$. All materials were highly pure, electronic-grade materials. Irradiation was carried out in the hydraulic tube or peripheral target tube position of the High Flux Isotope Reactor (HFIR) within a perforated "rabbit" capsule. The rabbit capsule consists of an aluminum tube (the rabbit) which has 
large holes drilled through the wall to allow HFIR coolant water to flow through and contact its contents. The HFIR coolant water enters the core at $49^{\circ} \mathrm{C}$ and exits at $69^{\circ} \mathrm{C}$. Samples were located mid-core such that the exterior of the samples should be just above $60^{\circ} \mathrm{C}$. Samples were irradiated in a fast neutron dose range from $2 \times 10^{23}$ to $2 \times 10^{26} \mathrm{n} / \mathrm{m}^{2}(\mathrm{E}>0.1 \mathrm{MeV})$ at a fast neutron flux of approximately $1 \times 10^{19}$ $\mathrm{n} / \mathrm{m}^{2} \mathrm{~s}$ corresponding to approximately $10^{-6} \mathrm{dpa} / \mathrm{s}$. For this paper an equivalence of $1 \mathrm{x} 10^{25} \mathrm{n} / \mathrm{m}^{2}(\mathrm{E}>0.1 \mathrm{MeV})=1$ displacement per atom (dpa) is assumed. Square samples of approximately $6 \mathrm{~mm}$ on edge were used. The CVD SiC materials were nominally $2.8 \mathrm{~mm}$ thick while the $\alpha-\mathrm{SiC}, \beta$-SiC and $\mathrm{Si}$ samples were cut from wafers of $0.2 \mathrm{~mm}, 0.1 \mathrm{~mm}$, and $0.5 \mathrm{~mm}$ thickness, respectively.

Following neutron irradiation the samples were removed from the rabbit container and ultrasonically cleaned first with ethyl alcohol and then immersed in hydrofluoric acid for approximately 30 minutes to remove any glassy surface layer that may have been present. Prior to x-ray examination samples were wrapped in kapton for radioactive contamination control. Lattice parameters of single crystals were measured using x-ray diffraction. X rays were generated using a Rigaku R200 generator with a Cu target operating at $45 \mathrm{kV}$ and $100 \mathrm{~mA}$. A Ge (220) crystal monochromator with slits selected for $\mathrm{Cu} \mathrm{K}_{\alpha 1}$ incident beam. The sample was mounted in reflection geometry on a 4-circle diffractometer; the angle of diffracted $\mathrm{x}$-rays was determined using a Ge (220) crystal analyzer. X rays were counted using a $\mathrm{NaI}(\mathrm{Tl})$ scintillation detector. Instrumental resolution is $0.005^{\circ}$ in $2 \theta .2 \theta$ scans were taken for a series of Bragg reflections: (111), (002), (202), (113), (311), and

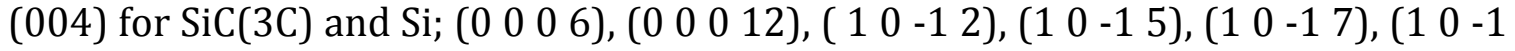
10), (1 1 -2 6), and (2 $0-24)$ for $\operatorname{SiC}(6 \mathrm{H})$. The center of each Bragg reflection was found by least-squares fitting to a Gaussian profile. The lattice parameters were determined using a least-squares refinement of angles calculated using Bragg's law to measured Bragg angles. Swelling magnitude, determined based on $\mathrm{X}$ ray data, was quantified using the changes in these lattice parameters $(5$ reflections for the cubic materials and 7-9 reflections for the hexagonal materials) as a function of dose.

The microstructure of certain specimens were observed using transmission electron microscopy (field emission type JEM2100F at 200kV). TEM foils were prepared using a focused ion beam system (FEI Versa 3D Dual Beam) operated at $30 \mathrm{kV}$ for initial milling and at $2-5 \mathrm{kV}$ for final thinning.

Physical dimensions were measured before and after irradiation using calibrated micrometers. However, a density gradient column (DGC) was utilized to determine (and report) immersion bulk density with calibrated floats and mixtures of methylene iodide and tetrabromomethane with much greater accuracy. It is noted that density calculated from physical dimensions and dry weight were in agreement. A representative column section is provided in Figure 1. The denser, non-irradiated $\mathrm{SiC}$ samples are provided in the left of the figure. As observed, the non-irradiated $\alpha-6 \mathrm{H}, \beta-3 \mathrm{C}$ and CVD faulted $\beta$ exhibit a very close grouping as did the irradiationdarkened $0.5 \mathrm{dpa}$ samples of the right figure. Measurements were repeatable 
through multiple columns. A typical density gradient as shown for the column of figure 1 was $0.002\left(\mathrm{~g} / \mathrm{cm}^{3}\right)$ per centimeter of column length. Error associated with the density measurement, assuming no sample surface contamination, for such a column is less than $0.001 \mathrm{~g} / \mathrm{cm}^{3}$ or $<0.03 \%$.
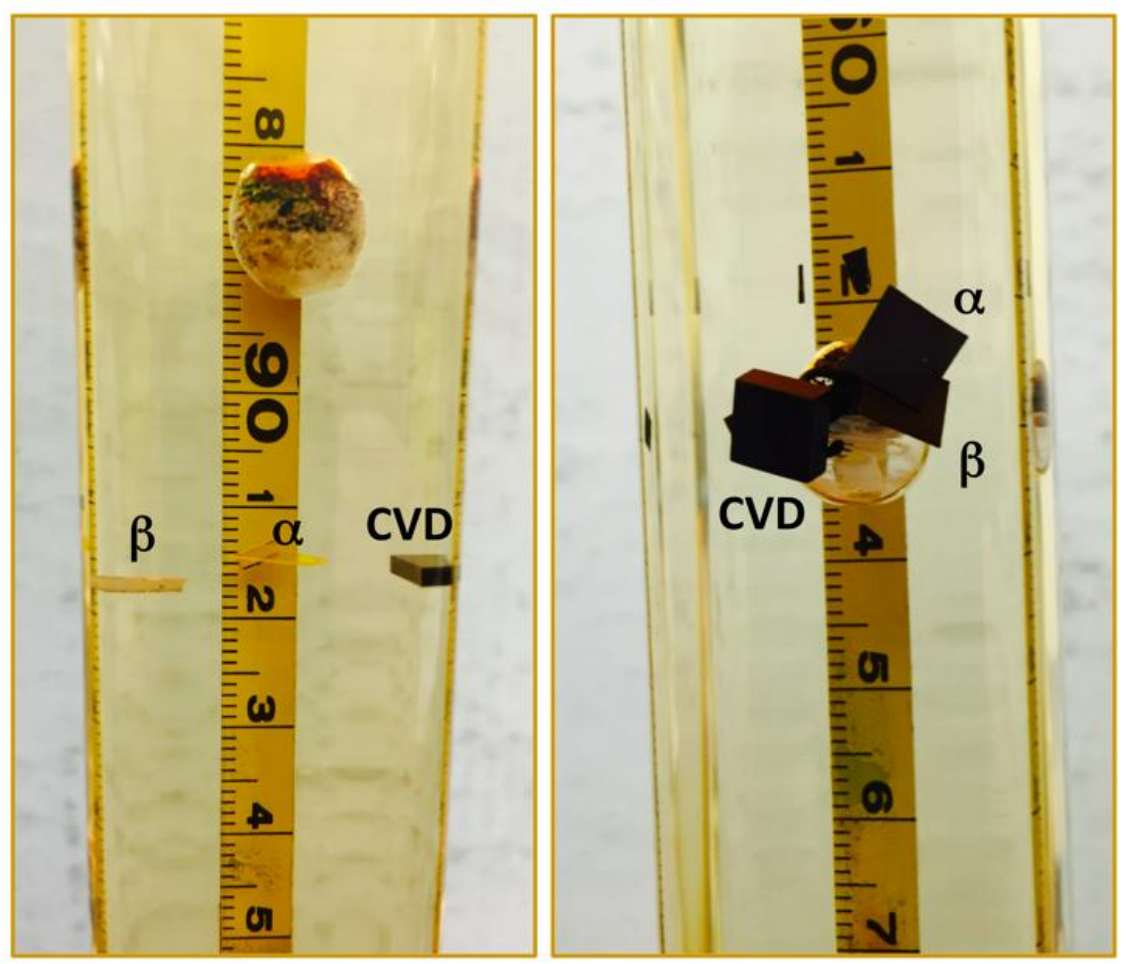

Figure 1 : Density gradient column with calibrated floats and groupings of nonirradiated and 0.5 dpa irradiated $\mathrm{SiC}$ samples.

3. Results and Discussion

The dilation of the $<\mathrm{a}>$ and $<\mathrm{c}>$ axes of $\alpha-6 \mathrm{H}-\mathrm{SiC}$ as compared to non-irradiated is shown in Figure 2. From the figure a monotonic expansion occurs along both axes to a dose level of $0.5 \times 10^{25} \mathrm{n} / \mathrm{m}^{2}(\mathrm{E}>0.1 \mathrm{MeV})$. Above each irradiated sample data point within the figure the percent expansion is provided. By comparing the $<\mathrm{a}>$ and $<c>$ axes percent expansion and noting that the differences are within the combined $\mathrm{x}$-ray technique and computational error it is clear that the irradiation-induced lattice dilation for each orientation of the $\alpha-6 \mathrm{H}-\mathrm{SiC}$ is identical. 


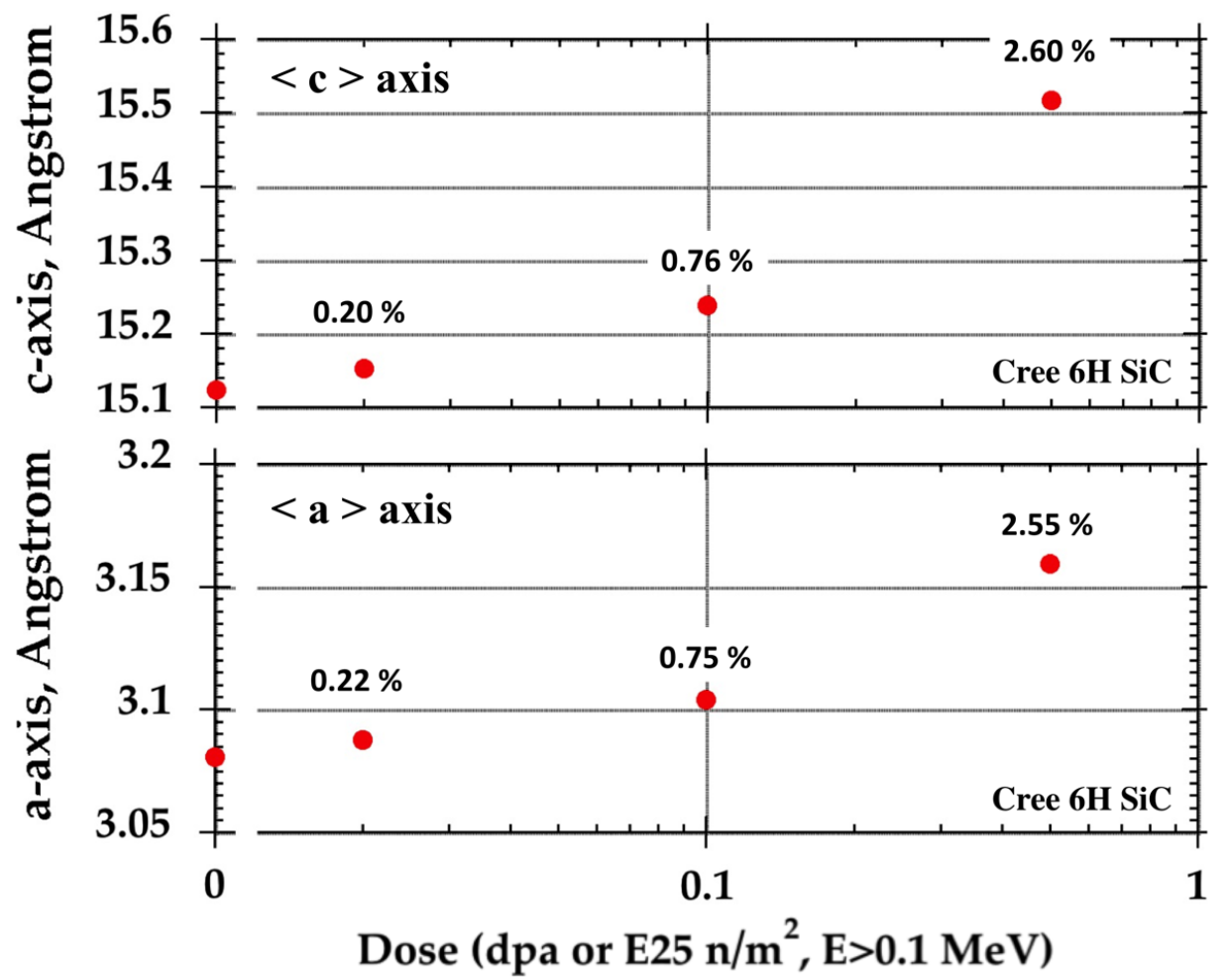

Figure 2: Irradiation-induced dilation of the $<\mathrm{a}>$ and $<\mathrm{c}>$ axis of $\alpha-6 \mathrm{H}-\mathrm{SiC}$.

As understood from a large body of previous work[10] the initial irradiationinduced swelling of $\mathrm{SiC}$ for irradiation temperatures less than $\sim 1000^{\circ} \mathrm{C}$ increases per a power law and then approaches a saturation level by a few dpa $\left(\sim 2 \times 10^{25} \mathrm{n} / \mathrm{m}^{2}\right.$ $\mathrm{E}>0.1 \mathrm{MeV}$ ). This relative volume change is highly dependent on temperature, exhibiting enhanced swelling at lower temperature irradiation due to a larger fraction of residual interstitial complexes remaining following neutron-induced cascade events at the lower temperatures.[23] Data on the effect of irradiation on bulk swelling of CVD faulted $\beta$-SiC as measured by DGC is provided in Figure 3 as solid square data points. For the irradiation temperature of this study, $\sim 60^{\circ} \mathrm{C}$, the exaggerated swelling at lower temperature is clearly observed. For the $0.02,0.1$ and 0.5 dpa doses, the single crystal $\alpha-6 \mathrm{H}$ and $\beta-3 \mathrm{C} \mathrm{SiC}$ bulk swelling was essentially identical to that of the faulted- $\beta$ CVD SiC (depicted in Figure 1, not plotted in Figure 3 for the sake of clarity.) The power-law rate constant of swelling with dose, approximately 0.77 , agrees well with 0.81 found in the previous work of Katoh et al.[24] for Ni-ion irradiation (at $\sim 100^{\circ} \mathrm{C}$.) For this temperature range it is assumed that there is no vacancy mobility on either the silicon or carbon sublattice and that only the carbon interstitial is mobile. Under these conditions Katoh has previously discussed the power law rate constant for swelling accumulation[25] as being either $2 / 3$ for the formation of two-dimensional defects or $3 / 5$ for the formation of three-dimensional defect agglomerates. In the more limiting case where the irradiation temperature is reduced and the carbon interstitial also become immobile the rate constant would approach unity. 
Swelling data calculated from the single crystal diffractometry measurements is provided next to the first three dose data points of Fig 3. As can be seen from the figure the irradiation-induced volume change measured through bulk (DGC) means or by x-ray density are essentially identical and the equivalence of the $\alpha-6$ 国国国目 and $\beta-3 \mathrm{X}$ SiC swelling is also observed through comparison of the X-ray data.

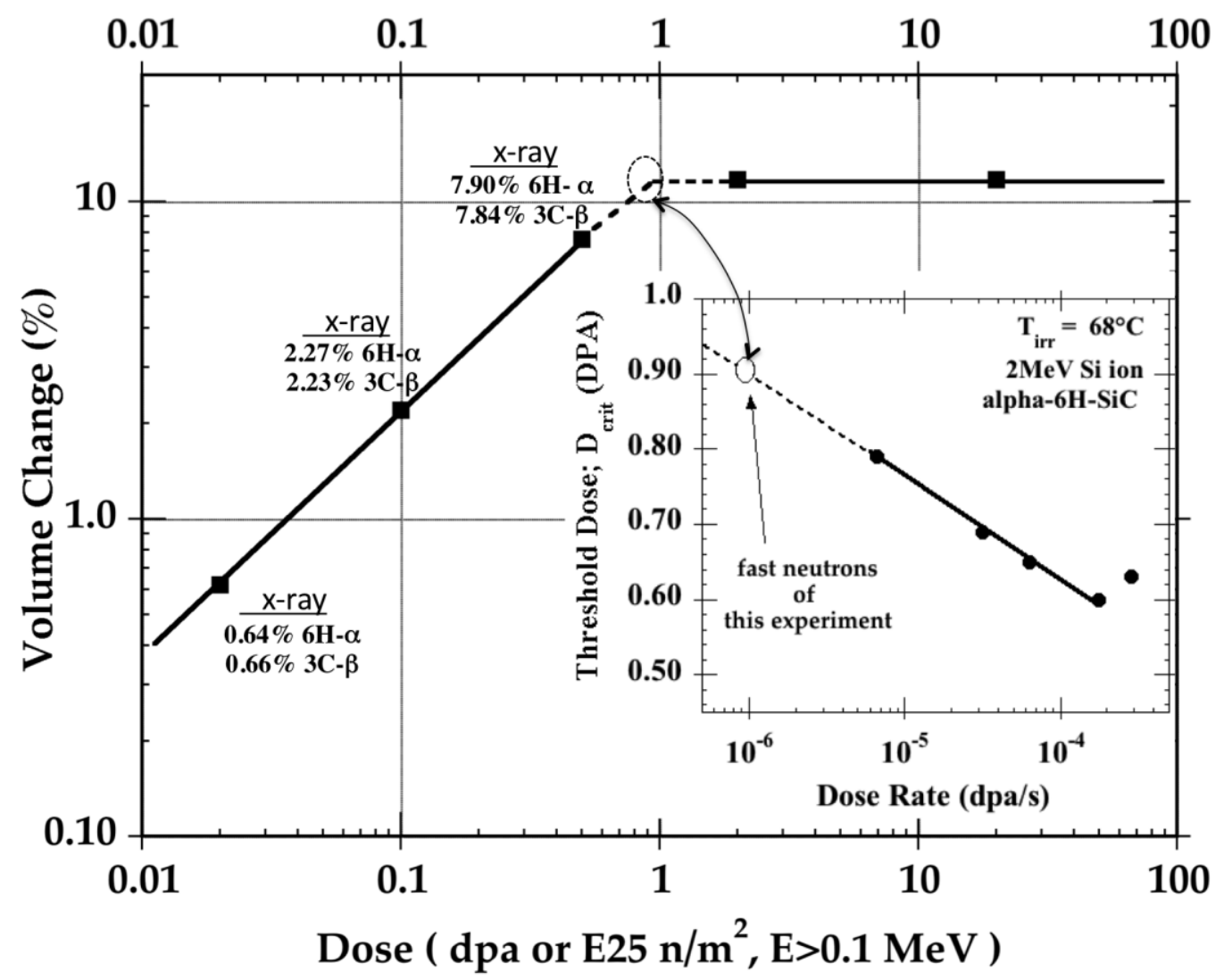

Figure 3: Irradiation-induced swelling of faulted $\beta$ CVD SiC inset with effect of dose rate on threshold dose for Si ion irradiation on $\alpha-6 \mathrm{H} \mathrm{SiC}[26]$.

Also of note from Fig. 3 is the significant swelling that occurs in SiC (7.8\%) at 0.5 dpa. Though these samples undergo impressive irradiation-induced lattice strain, X-ray and TEM analysis indicates that the remains crystalline at that dose. Figure 4 provides a high-resolution TEM image of the $0.5 \mathrm{dpa}$ irradiated single crystal $6 \mathrm{H}-\mathrm{SiC}$. Close inspection of the micrograph does suggest the formation of discontinuous pockets of highly damaged areas that may evolve into amorphous regions. Moreover, the diffraction profiles for the $0.5 \mathrm{dpa} \alpha-6 \mathrm{H}-\mathrm{SiC}$ suggests a level of

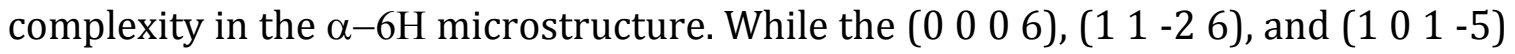

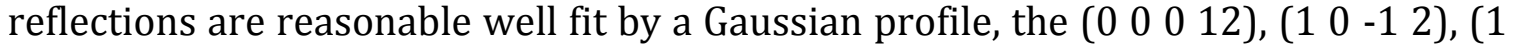
$0-17)$, and (1 $0-110)$ reflections have a double-peak profile, with a splitting $\Delta d / d$

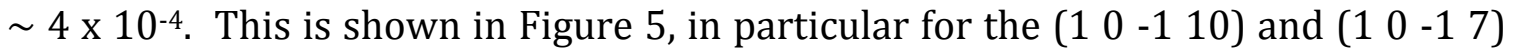
reflections, giving the progression from non-irradiated, $0.1 \mathrm{dpa}$, to $0.5 \mathrm{dpa}$, clearly 
showing a peak splitting at the $0.5 \mathrm{dpa}$ irradiation damage level. Lattice parameters were determined by fitting line-shapes to a profile with two Gaussian peaks and including both peaks in the lattice parameter refinement, giving some sort of average lattice parameter. Peak splitting in this sample is accompanied by lower intensities: the (2 $0-24)$ reflection was too weak to be measured. Line-shapes for all other samples are reasonably fit by a single Gaussian. It is currently unclear what defects give rise to this splitting. However, it has been previously noted[19] [27] in heavy ion irradiation studies that a two-stage progression occurs in the amorphization regime for $\mathrm{SiC}$ whereby the swelling progresses from point-defect formation (Stage 1) into an amophization regime (Stage 2) at a dose slightly lower than the $0.5 \mathrm{dpa}$ where the Bragg-peak splitting was observed in this study. Unfortunately the gap between the 0.1 and $0.5 \mathrm{dpa}$ was too large to directly observe or confirm this previous observation.

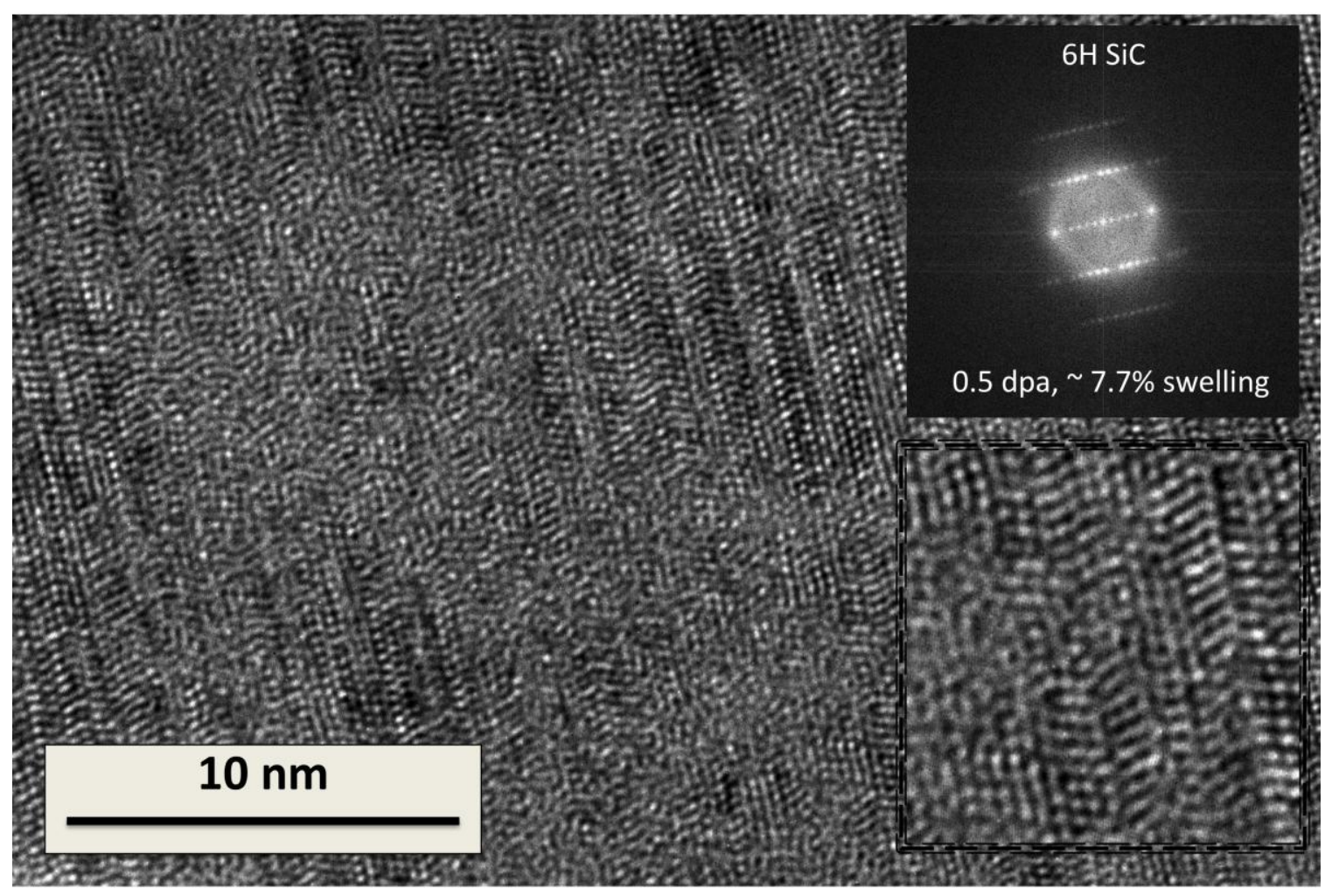

Figure 4 : High resolution TEM of high-swelling $0.5 \mathrm{dpa} 6 \mathrm{H}-\mathrm{SiC}$. 


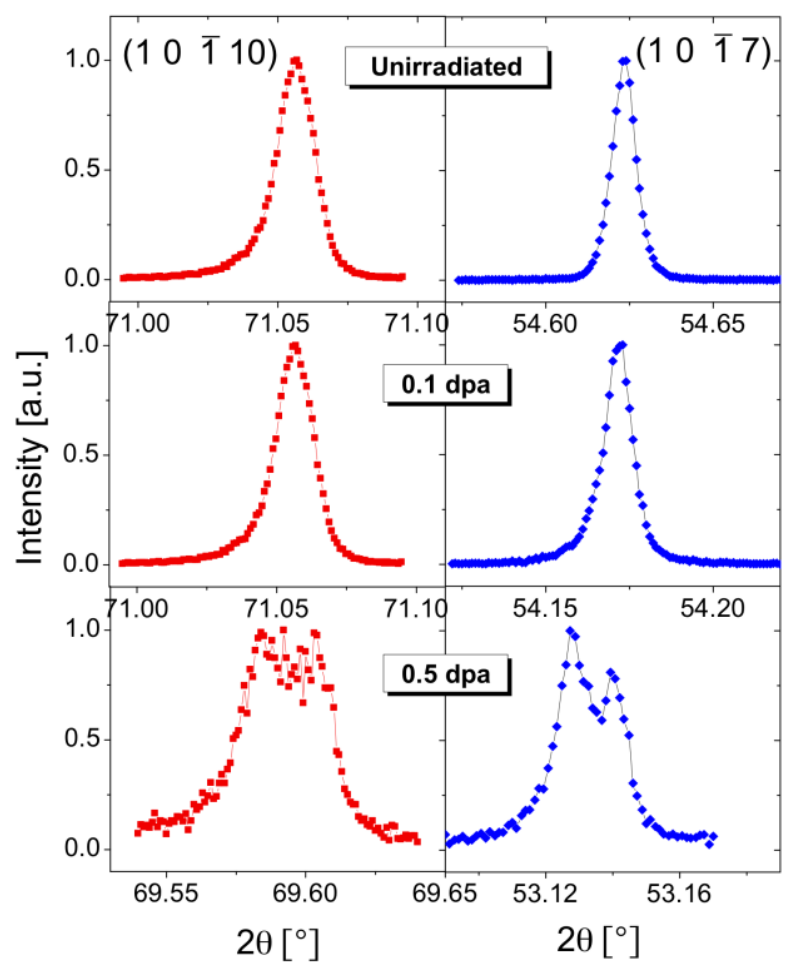

Figure 5 : Diffraction peaks for non-irradiated, 0.1 , and 0.5 dpa materials indicating

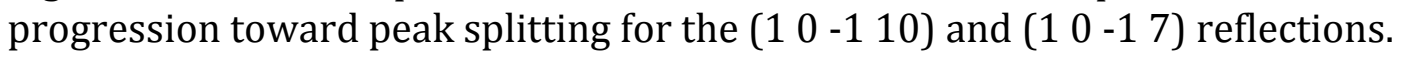

The measured 7.8\% swelling for the neutron irradiated SiC of figure 3, while a remarkably high strain for the crystal to manage, and to the authors knowledge the highest neutron-induced swelling of $\mathrm{SiC}$ reported, has been previously reported for ion irradiated $\mathrm{SiC}$. Katoh et al.[24] carried out a series of $4 \mathrm{MeV} \mathrm{Ni}$ ion and $\mathrm{Ni}-\mathrm{He}$ dual ion implantation experiments on $\beta-3 \mathrm{C}$ SiC to determine the effects of He on swelling. In that work, carried out at approximately the same temperature as the present work, the material remained crystalline up to approximately $1.07 \mathrm{dpa}$, which was defined as the threshold amorphization temperature above which the materials made the amorphous transition with a resulting $\sim 12.8 \%$ swelling. In that work the maximum reported swelling prior to amorphization (at $1.07 \mathrm{dpa}$ ) was approximated as $7 \%$, consistent with the current work.

In contrast with the swelling of the $\mathrm{SiC}$, the $\mathrm{Si}$ samples of the present study showed essentially no change for the irradiation conditions studies. The Si sample irradiated to a dose of 20 dpa yielded a bulk density through DGC nearly identical to non-irradiated while single crystal diffractometry for the sample irradiated to $2 \mathrm{dpa}$ yields an <a> axis changing from 5.43115 to 5.43126 Angstrom, or an approximate $0.002 \%$ expansion. Such a modest expansion is not surprising with previous authors reporting on essentially no change for a $380-700^{\circ} \mathrm{C}$ range irradiation[28] [12] in the dose range of the current study. 
Also seen in Figure 3, at some point above the 0.5 dpa dose level a transition from crystalline to amorphous $\mathrm{SiC}$ occurs. At the 2 dpa dose level all three $\mathrm{SiC}$ materials indicate complete amorphization, as determined through x-ray diffraction. Moreover, within experimental error the density for all SiC materials studied have equivalent density as measured by DGC for the 2 and 20 dpa dose levels, or $\sim 11.7 \%$ volume expansion $(2.84 \mathrm{~g} / \mathrm{cm} 3)$ : for a dose of greater than $10 \mathrm{x}$ the threshold amorphization dose no change in density occurs. It is noted that for previous work where neutron-amorphized SiC was annealed slightly above the irradiation temperature significant changes in a range of properties including density occured[29,30], indicating that amorphous $\mathrm{SiC}$ is a continuum of states depending on the variables by which amorphization is achieved. However, steady state density and by inference its short-range order appears to establish itself soon after amorphization occurs.

Amorphization of SiC has been widely studied and it is now understood that the dose required for the crystal-to-amorphous transition has a relatively strong dependence on temperature and a weaker dependence on irradiation spectrum, starting microstructure (whether $\alpha$ or $\beta$ initial crystal or impact of grain structure,) and chemical purity. The temperature dependence for amorphization is due to the onset of species mobility such as the carbon and silicon interstitials as indicated by a number of subtle dose inclines prior to onset of a rapid, asymptotic increase in dose with temperature. The minimum temperature-dependent dose at which amorphization occurs is referred to as the critical dose, having a minimum of $\sim 0.2$ dpa near liquid nitrogen temperature. The effect of temperature on critical dose has been studied for a number of irradiating species including $2 \mathrm{MeV}$ electrons,[31] [32] [33] $360 \mathrm{keV}$ argon [34] or $1.5 \mathrm{MeV}$ xenon ions[35,36] [34,37,38] and 0.56 MeV silicon-ions[39] [40] [41] The temperature dependence for critical dose for these previous studies were somewhat different, depending primarily on the ion, being in the range of $20^{\circ} \mathrm{C}$ and $70^{\circ} \mathrm{C}$ for electrons[31,32,42], $\sim 150^{\circ} \mathrm{C}$ for Si ions [40] [33] and $\sim 220^{\circ} \mathrm{C}$ for Xe ions.[36] The displacement damage rates for all of those studies were similar, on the order of $\sim 1 \times 10^{-3} \mathrm{dpa} / \mathrm{s}$ or about three orders of magnitude greater than the current neutron irradiation. It is noted that both Weber $[35,36]$ and Matsunaga's[43] work did not observe a significant difference in amorphization threshold between $\alpha$ - and $\beta$-SiC, whereas Inui did report a threshold temperature $\sim 50^{\circ} \mathrm{C}$ higher for faulted $\beta$-SiC.[31]

The neutron-amorphization of $\mathrm{SiC}$ and associated properties was first described by Snead et. al. $[29,44,45]$ As with the current work, materials were irradiated in contact with coolant water, though through inspection of large diameter specimens a critical amorphization temperature of $\sim 125^{\circ} \mathrm{C}$ was inferred,[46] in reasonable agreement with the Si ion results. [40] [33] This would be expected given the relative similarity of the sub-cascades produced by both fast neutrons and $2 \mathrm{MeV} \mathrm{Si}$ ions. However, in comparing the $\mathrm{Si}$-ion beams and neutron irradiation experiments the effect of dose rate must also be considered. Inset into Fig. 3 is included a dataset from work of Snead et al[26] who investigated the effect of damage rate on 
critical amorphization dose for Cree $\alpha-6 \mathrm{H}-\mathrm{SiC}$ using $2 \mathrm{MeV}$ Si ions implanted at $68^{\circ} \mathrm{C}$ (similar to the irradiation temperature of this study.) Of interest from the inset is the extrapolation of the dose dependent critical dose from that of the $\mathrm{Si}$ ion experiments to that of the current neutron irradiation experiments. With decreasing dose rate the critical dose is seen to increase linearly on the log dose plot, excepting the highest dose rate point that appears anomalous and was attributed to beam heating at the extremely high ion flux.[26] By extrapolating the previous Siion data back to the dose rate appropriate for the current neutron irradiation experiment $\left(\sim 1 \times 10^{-6} \mathrm{dpa} / \mathrm{s}\right)$ a critical threshold for amorphization of $\sim 0.9 \mathrm{dpa}$ is suggested. It is cautioned that whenever comparing neutron and ion irradiation data comparison using dpa must be considered approximate for a number of reasons including those associated with the use of SRIM as discussed recently by Stoller. [47] Further investigation to more precisely define the amorphization transition and to better define the flux dependence is an area for further research.

\section{Conclusion}

As demonstrated clearly in this work the irradiation-induced lattice strain for the most common crystal structures of interest for nuclear application, $\alpha-6 \mathrm{H}$ (alpha) and $\beta$-3C (beta) silicon carbide, have near identical irradiation swelling behavior near $60^{\circ} \mathrm{C}$. Single crystal alpha and beta $\mathrm{SiC}$ swelling was also equivalent to that of highly pure CVD SiC (a highly-faulted polycrystalline form of $\beta$-SiC.) Results of single crystal X-ray diffraction were confirmed by precise bulk density measurements of all materials. Moreover, the swelling along the $<a>$ and $<c>$ axis of $\mathrm{SiC}$ polytypes demonstrates the isotropic swelling behavior of both alpha-6H and beta-3C SiC. Parallel irradiation of single crystal Si to 20 dpa indicated essentially no change in lattice spacing or bulk swelling.

At a level of $0.5 \mathrm{dpa}$ all $\mathrm{SiC}$ materials underwent an extraordinarily large swelling $(>7.8 \%)$ while remaining crystalline. At some dose beyond this point, assumed to be $\sim 0.9 \mathrm{dpa}$, the $\mathrm{SiC}$ crystal transitions to an amorphous structure with a resulting $11.7 \%\left(2.84 \mathrm{~g} / \mathrm{cm}^{3}\right)$ swelling. Alpha- $6 \mathrm{H}$, beta-3C, and polycrystalline CVD SiC all resulted in a similar density upon amorphization with a similar density measured at the 2.0 and $20 \mathrm{dpa}$, suggesting that the short-range order of $\mathrm{SiC}$ saturates soon after amorphization occurs.

The overall findings of this study, combined with understanding that can be gleaned from the literature, suggests that the common $\mathrm{SiC}$ polytypes and the ceramics derived from them are similar in the irradiation stability and for the purposes of engineering ceramics should be treated as equivalent for low temperature irradiation. 


\section{Acknowledgement}

The work presented in this manuscript was supported by the Advanced Fuels Campaign of the Fuel Cycle R\&D program in the Office of Nuclear Energy, US Department of Energy through a contract with the University of Tennessee, Knoxville. The author would like to thank Dr. Steven Zinkle and Brian Wirth for assistance with the manuscript. Transmission electron microscopy was supported by ORNL's Shared Research Equipment (ShaRE) User Facility, which is sponsored by the Scientific User Facilities Division, Office of Basic Energy Sciences, US Department of Energy. Irradiations were carried out in the High Flux Isotope Reactor, an user facility funded by the Office of Science, US Department of Energy. 
References

[1] F. W. Clinard, W. Dienst, E. H. Farnum, J Nucl Mater., 212-215, (1983) 1075.

[2] R. A. Matheny, J. C. Corelli, J Nucl Mater., 83, (1979) 313.

[3] W. G. H. R. B. Matthews, F. Havelock, Journal of the Canadian Ceramic Society, 42, (1973) 1.

[4] W. Dienst, J Nucl Mater., 191-194, (1992) 555.

[5] D. S. Tucker et. al., J Nucl Mater., 141-146, (1986) 401.

[6] T. Yano et. al., J Nucl Mater.s, 289, (2001) 102.

[7] T. Yano, T. Iseki, J Nucl Mater., 203, (1993) 249.

[8] B. S. Hickman. Radiation Effects in Beryllium and Beryllium Oxide. In Studies in

Radiation Effects; G. J. Dienes, Ed.; Gordon and Breach, 1966; Vol. 1; pp 72.

[9] B. S. Hickman, D. G. Walker, J Nucl Mater., 18, (1966) 1966.

[10] L. L. Snead et. al., J Nucl Mater., 371, (2007) 329.

[11] R. B. Matthews, W. G. Hutchings, J Nucl Mater., 45, (1972) 341.

[12] R. Matthews, J. Nucl. Mater., 51, (1974) 203.

[13] T. Iseki et. al., J Nucl Mater., 170, (1990) 95.

[14] R. J. Price, G. R. Hopkins, J Nucl Mater., 108-109, (1982) 732.

[15] W. Dienst, H. Zimmermann, J Nucl Mater., 212-215, (1994) 1091.

[16] J. C. Corelli et. al., J. Amer. Ceram. Soc., 66, (1983) 529.

[17] Y. R. Lin et. al., J Nucl Mater., 455, (2014) 292.

[18] W. Jiang et. al., Applied Physics Letters, 91, (2007) 091918.

[19] J.-M. Costantini et. al., Journal of Physics D: Applied Physics, 45, (2012) 465301.

[20] X. Kerbiriou et. al., Journal of Applied Physics, 105, (2009) 073513.

[21] Y. Pramono, K. Sasaki, T. Yano, Journal of Nuclear Science and Technology, 41, (2004) 751.

[22] R. J. Price, J Nucl Mater., 33, (1969) 17.

[23] Y. Katoh et. al., Current Opinion in Solid State and Materials Science, 16, (2012) 143.

[24] Y. Katoh, H. Kishimoto, A. Kohyama, J Nucl Mater., 307-311, (2002) 1221.

[25] Y. Katoh et. al., J Nucl Mater., 448, (2014) 448.

[26] L. L. Snead et. al., Materials Research Society Symposium Proceedings, 540, (1999) 165.

[27] J. Jagielski, L. Thomé, Applied Physics A, 97, (2009) 147.

[28] T. Yano, Y. Yamamoto, T. Iseki, J Nucl Mater., 307-311, (2002) 1102.

[29] L. L. Snead, S. J. Zinkle, Nucl. Instrum. Meth. in Phys Res., B 191, (2002) 497.

[30] M. Ishimaru et. al., Physical Review Letters, 89, (2002) 055502.

[31] H. Inui, H. Mori, H. Fujita, Philosophical Magazine B, 61, (1990) 107.

[32] H. Inui et. al., Philosophical Magazine B, 65, (1992) 1.

[33] C. Kinoshita, et. al. Proceedings of the 11th International Conference on Electron Microscopy, 1986.

[34] W. J. Weber et. al., J Nucl Mater., 244, (1997) 258.

[35] W. J. Weber, L. M. Wang, Nucl. Instrum. Meth. Phys. Res. B, 106, (1995) 298.

[36] W. J. Weber, L. M. Wang, N. Yu, Nucl. Instrum. Meth. Phys. Res. B, 116, (1996) 322. 
[37] W. J. Weber, N. Yu. "In-Situ study of the accumulation of ion-beam-induced damage in single crystal 3C silicon carbide"; Materials Science Forum. 239-241 (1997) 155-158.

[38] W. J. Weber, N. Yu, L. M. Wang, J Nucl Mater., 253, (1998) 53.

[39] L. L. Snead, S. J. Zinkle. Amorphization and the Effect of Implanted Ions in SiC. In MRS Symposium on Microstructure of Irradiated Materials; I. M. Robertson, L. E.

Rehn, S. J. Zinkle, W. J. Phythian, Eds.; MRS: Pittsburgh, 1995; Vol. 373; pp 377. [40] L. L. Snead, S. J. Zinkle. Threshold irradiation dose for amorphization of silicon carbide. In Microstructure Evolution During Irradiation; I. M. Robertson, G. S. Was, L. W. Hobbs, T. D. d. l. Rubia, Eds.; Materials Research Society: Pittsburgh, 1997; Vol. 439; pp 595.

[41] S. J. Zinkle, L. L. Snead, Nuclear Instruments and Methods in Physics Research B, 116, (1996) 92.

[42] H. Inui, H. Mori, H. Fujita, Acta Metallurgica, 37, (1989) 1337.

[43] A. Matsunaga et. al., Journal of Nuclear Materials, 179-181, (1991) 457.

[44] L. L. Snead et. al., Nuclear Instruments and Methods in Physics Research B, 141, (1998) 123.

[45] L. L. Snead et. al. Threshold dose for amorphization of silicon carbide. In Microstructure Evolution During Irradiation; I. M. Robertson, G. S. Was, L. W. Hobbs, T. Diaz de la Rubia, Eds.; Materials Research Society: Pittsburgh, 1997; pp 595. [46] L. L. Snead, J. C. Hay, J. Nucl. Mater., 273, (1999) 213.

[47] R. E. Stoller et. al., Nuclear Instruments and Methods in Physics Research Section B: Beam Interactions with Materials and Atoms, 310, (2013) 75. 